\title{
Analytical Quantification of Electrochemical Ferrates for Drinking Water Treatments
}

\begin{tabular}{|r|l|}
\hline Journal: & Canadian Journal of Chemistry \\
\hline Manuscript ID & cjc-2016-0315.R2 \\
\hline Danuscript Type: & Article \\
\hline Complete List of Authors: & $\begin{array}{l}\text { Cataldo Hernandez, Macarena; University of British Columbia, Chemical } \\
\text { and Biological Engineering } \\
\text { May, Andrew; University of British Columbia, Chemical and Biological } \\
\text { Engineering } \\
\text { Bonakdarpour, Arman; University of British Columbia, Chemical and } \\
\text { Biological Engineering } \\
\text { Mohseni, Madjid; University of British Columbia, Chemical and Biological } \\
\text { Engineering } \\
\text { Wilkinson, David P.; University of British Columbia, Chemical and Biological } \\
\text { Engineering }\end{array}$ \\
\hline Keyword: & \begin{tabular}{l} 
ferrates, electrochemical, Drinking water, analytical quantification \\
\hline
\end{tabular} \\
\hline
\end{tabular}




\section{Analytical Quantification of Electrochemical Ferrates for}

\section{Drinking Water Treatments}

3 Macarena A. Cataldo Hernández*, Andrew May, Arman Bonakdapour, Madjid Mohseni, David 
16 Abstract

17 Ferrate ions are a highly oxidizing and unstable species which are challenging to quantify and

18 analyze. They are, however, becoming increasingly recognized as an excellent candidate for a

19 number of applications such as for water treatment. A wider acceptance of ferrates requires an

20 accurate assay of the produced ferrates. We report on four analytical methods (existing and new)

21 for quantification of ferrates and discuss their advantages and disadvantages. These methods

22 include titrimetric analysis, and spectrometric techniques such as direct colorimetric,

23 measurements of ABTS or NaI colorimetric. In terms of accuracy, cost, simplicity and time

24 required the modified indirect $\mathrm{UV}-\mathrm{Vis} / \mathrm{NaI}$ method is shown to be the most effective of all the

25 four methods investigated.

26 KEYWORDS: ferrates, chemical, electrochemical, analytical quantification, titration, UV-Vis

27 absorption, water treatment. 
38 Graphical Abstract

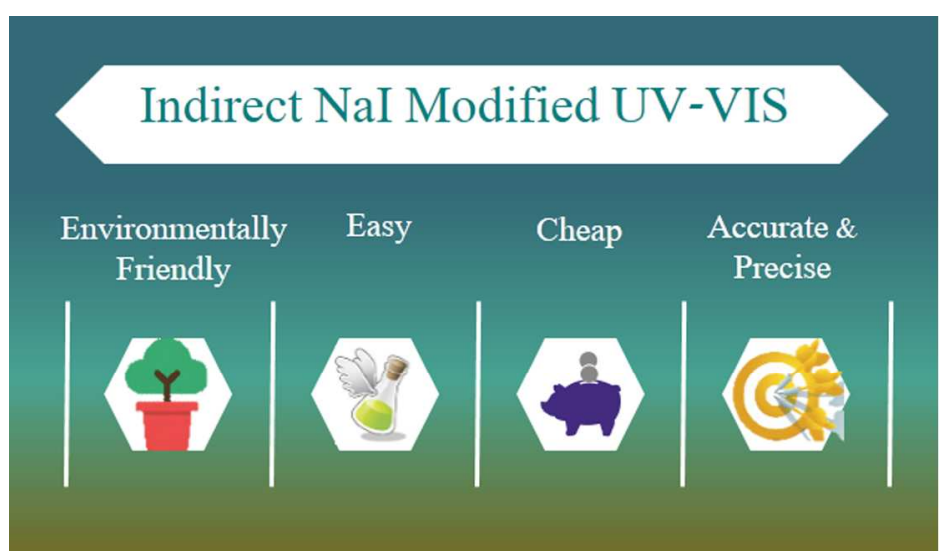

39

40

41

42

43

44

45

46

47

48

49

50

51

52

53

54

55

https://mc06.manuscriptcentral.com/cjc-pubs 


\section{Introduction}

Currently, many remote and indigenous communities in Canada face inadequate access to

58 drinking water. The NSERC-supported Res'eau WaterNET, is a nationally-funded strategic

59 research network in Canada, which is dedicated to solving remote community drinking water

60 challenges. The network activities include development of innovative treatment processes, water

61 health assessment and monitoring, and governance/risk management. One of the technologies

62 currently under investigation by the Res'EAU Network is the on-site electrosynthesis of ferrates

63 for disinfection processes

64 Ferrate anions are very suitable for use in drinking water treatment. In particular, they have

65 been shown to be very effective in the removal of Escherichia Coli, fecal coliform, sulphur and

66 nitrogen containing contaminants ${ }^{1}$ and toxins ${ }^{2}$.

67 The suitability of ferrates is a consequence of their unique properties such as: a) a high

68 standard half-cell reduction potential (2.20 V vs. SHE), b) non-toxic reduction byproducts $\left(\mathrm{Fe}^{3+}\right)$,

69 and c) the simultaneous capacity to act as both an oxidant and coagulant agent ${ }^{3}$. Ferrate anions

70 can exist in several oxidation states: $\left[\mathrm{FeO}_{4}\right]^{2-}$ in the Fe (VI) state, $\left[\mathrm{FeO}_{4}\right]^{3-}$ in the Fe (V) state or

$\left.71 \mathrm{FeO}_{4}\right]^{4-}$ in the $\mathrm{Fe}(\mathrm{IV})^{1}$ state. The $\mathrm{Fe}(\mathrm{VI})$ state is known to be the most stable and common

72 form, thus the terms ferrate and Fe (VI) are used interchangeably hereinafter. During an

73 oxidation process, the ferrate (VI) ions reduce to Fe (III) ions or ferric hydroxide, hence

74 generating a coagulant ${ }^{4}$.The redox potential of ferrate (VI) ions is greater than other commonly

75 used oxidizing agents in water treatment such as chlorine (1.358 V vs. SHE) and ozone (2.076 V

76 vs. SHE) ${ }^{5}$. Challenges with the use of traditional chlorination treatment processes include high

77 dosages and long contact time, which lead to the formation of carcinogenic disinfection by-

78 products (DBPs) such as trichloromethanes ${ }^{1}$. Thus, alternative methods of water disinfection are 
79 highly desired. Ozonation is an alternative disinfection method, but it is ineffective in alkaline

80 conditions and may result in the formation of carcinogenic bromates when bromides ions are

81 present in water ${ }^{1}$. The high oxidation potential, disinfectant strength and coagulant properties of

82 ferrates, make it a promising reagent for use in water purification ${ }^{6}$.

83 Traditional production of ferrates can be achieved by wet or thermal synthetic methods.

84 However, there are a number of disadvantages associated with these methods ${ }^{7,8}$. In the wet

85 chemical method, chlorine gas is passed through an iron-containing concentrated strong alkaline

86 solution (e.g., $\mathrm{NaOH}$ ) to generate hypochlorite. Subsequently, iron (III) is oxidized into iron (VI)

87 or ferrate. This process has a is relatively low yield (10-15\%) and additional reagents and further

88 steps are required to further purify and separate the desired product, leading to high costs ${ }^{1}$. On

89 the other hand, dry thermal synthesis of ferrate (VI) is performed at elevated temperatures (370

$90{ }^{\circ} \mathrm{C}$ ), and is considered to be expensive because of high energy consumption, and it is dangerous

91 due to potential detonation at high temperatures ${ }^{8}$. Since the stability of $\mathrm{Fe}(\mathrm{VI})$ is sensitive to

92 temperature, elevated temperatures also increase the decomposition rate of ferrate species.

93 Electrochemical generation of ferrates is an attractive alternative method of preparation,

94 because it requires neither hazardous reagents nor high temperatures. Ferrate (VI) can be

95 synthesized electrochemically by using either an inert electrode in a Fe (III) solution ${ }^{9,10}$, or a

96 dissolving iron anode ${ }^{11}$. The sacrificial anode (dissolving iron anode) is the more widely studied

97 approach. The process is conducted in a highly alkaline solution such as $10 \mathrm{M} \mathrm{NaOH}$ (or $\mathrm{KOH}$ ),

98 with an electric current serving to oxidize the iron to Fe (VI) according to following reaction:

$99 \mathrm{Fe}(0)+8 \mathrm{OH}^{-} \rightarrow \mathrm{FeO}_{4}{ }^{2-}+4 \mathrm{H}_{2} \mathrm{O}+6 \mathrm{e}^{-} \quad \Delta \mathrm{E}^{0}=0.8 \mathrm{~V} \quad$ vs. SHE

100 The second approach uses inert high oxidation potential (HOP) anode electrodes to increase the 101 current efficiency ${ }^{9}$. When dissolved $\mathrm{Fe}^{3+}$ is used as the source starting component, only three 
102 electrons are necessary to achieve the required $\mathrm{Fe}^{+6}$ oxidation state ${ }^{3,7}$ according to the following 103 reaction:

106 Although, electrochemical synthesis of $\mathrm{Fe}^{6+}$ is very promising for water treatment applications,

107 the common quantification methods for the electrochemically-generated ferrates face a number

108 of challenges such as high $\mathrm{pH}$ conditions, low concentration of ferrates ( $\mu \mathrm{M}$ range), and the

109 presence of $\mathrm{Fe}^{3+}$. Most analytical techniques reported in the literature focus on the analysis of 110 solid ferrates. In this case solid ferrate can be dissolved to make the optimum solution for each

111 measurement method. In the case of electrochemical generated ferrate, the solution properties

112 depend on the synthesis conditions, and in some cases are far from the optimal conditions for

113 ferrate measurement using the conventional methods ${ }^{8,12,13}$. Different ferrate measurement 114 techniques include: i) the trimetric chromite method ${ }^{14}$, ii) amperometric-potentiometric 115 titration $^{15,16}$, iii) spectrometric techniques such as direct colorimetric ${ }^{12,17}$, iv) 2,2'-azino-bis(3116 ethylbenzothiazoline-6-sulfonate) $\operatorname{ABTS}^{18}$, and v) iodide colorimetric ${ }^{6,8,15}$. However, titrimetric 117 analysis is time consuming, and requires at least $10 \mathrm{~mL}$ of solution, and it generates large 118 amounts of chemical waste. Some of the challenges facing the colorimetric methods include the 119 interference of colloidal $\mathrm{Fe}^{3+}$ oxides with the spectral measurements and poor response to low $(\sim$ $120 \mu \mathrm{M}$ ) iron concentrations ${ }^{12,13}$. The ABTS method has a lower detection limit and is stable in 121 several aqueous matrix systems including synthetic and natural water, however ABTS solution 122 are unstable and must be used within 30 minutes after preparation ${ }^{12,13,18}$. The conventional NaI 123 method is only applicable for quantification of ferrate in the $\mathrm{pH}$ range of $5.5-9.3^{12,13}$, making its 124 application in high $\mathrm{pH}$ electrochemical ferrate solutions unsuitable. However, given $\mathrm{NaI}$ is just a 
125 simple inorganic salt, in comparison with the more complex organic ABTS method, it would be

126 advantageous to improve this technique for use over a wide range of $\mathrm{pH}$ for ferrate solutions.

128 The objectives of the research presented in this paper were: i) to test and modify appropriately 129 different analytical techniques for ferrate quantification in solutions, and ii) to compare these

130 ferrate quantification methods for their cost, accuracy, precision, time, and waste produced. The 131 best quantification technique(s) for ferrate solutions with different $\mathrm{pH}$ conditions, in the presence 132 of Fe (III) were determined, in terms of performance, ease of application and economic and 133 environmental impact.

\section{2. Experimental}

135 For the generation of electrochemical ferrates, a two compartment glass cell was used as a 136 bench-top electrochemical reactor to generate ferrates. The cathodic and anodic compartments 137 were separated with a cation exchange membrane (Nafion NR-112). Carbon steel (AISI 1008, 138 Metal Supermarket Vancouver) was used as the anode and stainless steel (SS 304 Metal 139 Supermarket Vancouver) as the cathode. Both electrodes had dimensions of $1.50 \mathrm{~cm} \times 5.0 \mathrm{~cm}$. 140 The cathodic and anodic compartments each had a volume of $80 \mathrm{~mL}$ and the electrolyte used was $14114 \mathrm{M} \mathrm{NaOH}$, in deionized water (DI) with $18 \mathrm{M} \Omega$ purity. The electrochemical experiments were 142 performed galvanostaticaly at $10 \mathrm{~mA} \mathrm{~cm}^{-2}$ for 24 hours, using a Solartron (Model 1470E) 143 potentiostat.

144 For all the preparation and analytical methods the chemicals used were of analytical grade. 145 Preparation of the required solutions and the sample preparation are discussed below. 
147 For the titrimetric method three different solutions were used: a titrant solution, a 148 standardized solution and the sample solution.

149 1) Preparation of Fe (VI) containing solution

150 It was prepared using $10 \mathrm{~mL}$ of a solution of $720 \mathrm{~g} \mathrm{NaOH}$ in 1 liter of water, $5 \mathrm{~mL}$ of a solution

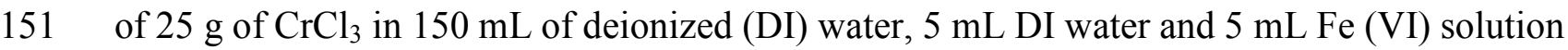

152 2) Preparation of the sample solution:

$15325 \mathrm{~mL}$ of $\mathrm{Fe}(\mathrm{VI})$ solution (for standardization of $25 \mathrm{~mL}$ of $\mathrm{K}_{2} \mathrm{Cr}_{2} \mathrm{O}_{7}$ solution), $60 \mathrm{~mL}$ of a 154 solution prepared using $20 \mathrm{~mL}(95-97 \%) \mathrm{H}_{2} \mathrm{SO}_{4}$ and $80 \mathrm{~mL}$ water $150 \mathrm{~mL}$ DI water $15 \mathrm{~mL}$ of an 155 acidic solution containing $150 \mathrm{~mL} \mathrm{85 \%} \mathrm{H}_{3} \mathrm{PO}_{4}$ were mixed with $60 \mathrm{ml} 95 \% \mathrm{H}_{2} \mathrm{SO}_{4}$ and $240 \mathrm{~mL}$ 156 water.

157 3) Preparation of indicator:

158 For the indicator, $0.32 \mathrm{~g}$ of sodium diphenylamine sulfonate were dissolved in $100 \mathrm{~mL}$ of DI 159 water.

160 4) Preparation of titrant:

$16133.36 \mathrm{~g}$ of $\left(\mathrm{NH}_{4}\right)_{2} \mathrm{Fe}\left(\mathrm{SO}_{4}\right)_{2} \cdot 6 \mathrm{H}_{2} \mathrm{O}$ were dissolved in $1 \mathrm{~L}$ of deionized water (about $\left.0.085 \mathrm{~N}\right)$. The 162 precise value for normality of the $\left(\mathrm{NH}_{4}\right)_{2} \mathrm{Fe}\left(\mathrm{SO}_{4}\right)_{2} \cdot 6 \mathrm{H}_{2} \mathrm{O}$ was determined by using this solution 163 to titrate a known sample solution containing $\mathrm{K}_{2} \mathrm{Cr}_{2} \mathrm{O}_{7}$. The $\mathrm{K}_{2} \mathrm{Cr}_{2} \mathrm{O}_{7}$ solution was prepared by 164 dissolving $1.042 \mathrm{~g}$ of the solid per $250 \mathrm{~mL}$ of DI water. From the titration of the $\mathrm{K}_{2} \mathrm{Cr}_{2} \mathrm{O}_{7}$ 165 solution using $\left(\mathrm{NH}_{4}\right)_{2} \mathrm{Fe}\left(\mathrm{SO}_{4}\right)_{2} \cdot 6 \mathrm{H}_{2} \mathrm{O}$, the precise normality was then determined from the 166 volume of $\mathrm{Fe}\left(\mathrm{NH}_{4}\right)_{2}\left(\mathrm{SO}_{4}\right)_{2} \cdot 6 \mathrm{H}_{2} \mathrm{O}$ titrant required to yield a color change from dark red to green 167 yellowish.

169 For the ABTS colorimetric method the following solutions are used: 
170 1) Preparation of stock solutions

171 The stock solution of 2,2'-azino-bis(3-ethylbenzothiazoline-6-sulfonate) (ABTS) reagent was

172 prepared by dissolving $0.1 \mathrm{~g}$ ABTS in $100 \mathrm{~mL}$ distilled water and stored at $4{ }^{\circ} \mathrm{C}$. The $\mathrm{pH} 4.1$

173 buffer solution was prepared by dissolving $3.43 \mathrm{~mL}$ of $\mathrm{CH}_{3} \mathrm{COOH}, 0.69 \mathrm{~g}$ of $\mathrm{NaH}_{2} \mathrm{PO}_{4}$, and 2.67

$174 \mathrm{~g}$ of $\mathrm{Na}_{2} \mathrm{HPO}_{4}$ in $100 \mathrm{~mL}$ of distilled water to yield $0.6 \mathrm{M}$ acetate and $0.2 \mathrm{M}$ phosphate. The

$175 \mathrm{Na}_{2} \mathrm{HPO}_{4} /$ Borate buffer solution was prepared by dissolving $0.01454 \mathrm{~g} \mathrm{H}_{3} \mathrm{BO}_{3}$ and $0.777 \mathrm{~g}$

$176 \mathrm{Na}_{2} \mathrm{HPO}_{4}$ in $250 \mathrm{~mL}$ distilled water.

177 2) Preparation of samples for absorbance measurement

$1785 \mathrm{~mL}$ of 4.1 buffer solution, $1 \mathrm{~mL}$ ABTS reagent and a ferrate sample volume between $5 \mu 1-25 \mu 1$

179 were added to a $25 \mathrm{~mL}$ volumetric flask. The $\mathrm{Na}_{2} \mathrm{HPO}_{4} /$ Borate buffer solution was then added

180 until the volume of the solution in the flask is $25 \mathrm{ml}$. The solution changes color to green due to

181 the formation of $\mathrm{ABTS}^{+}$.

182 For the sodium iodide method, a $\mathrm{pH} 9$ buffer was prepared by combining of $995 \mathrm{~mL}$ of $0.1 \mathrm{M}$

$183 \mathrm{Na}_{2} \mathrm{HPO}_{4}$ and $45 \mathrm{~mL}$ of $0.1 \mathrm{M} \mathrm{HCl}$. A $0.1 \mathrm{M}$ solution using anhydrous $\mathrm{NaI}$ (Alfa Aesar) was then

184 prepared with this buffer.

185 Absorption measurements for the direct UV-VIS, ABTS and NaI methods were performed at $186505 \mathrm{~nm}, 415 \mathrm{~nm}$ and $351 \mathrm{~nm}$, respectively, with a Cary 100 spectrophotometer using $1 \mathrm{~cm}$ quartz 187 UV cells. The methodologies for all of the different quantification techniques are schematically 188 shown in Figure 1.

\section{Results and discussion}

190 3.1. Chemical Titrimetric Fe (VI) Analysis (chromite)

191 The titrimetric method proposed by Schreyer et al.(J. M. Schreyer, G. W. Thompson', 1950) is 192 considered the most accurate method for quantification of ferrates, and has been used as a 
193 standard procedure to bench mark other methods. In this titration method, dissolved ferrates

194 oxidize chromite $\mathrm{Cr}^{3+}$ to chromate $\mathrm{Cr}^{6+}$

$195 \mathrm{Cr}(\mathrm{OH})_{4}{ }^{-}+\mathrm{FeO}_{4}{ }^{2-}+3 \mathrm{H}_{2} \mathrm{O} \rightarrow \mathrm{Fe}_{2}(\mathrm{OH})_{3}\left(\mathrm{H}_{2} \mathrm{O}\right)_{3}+\mathrm{CrO}_{4}{ }^{2-}+\mathrm{OH}^{-}$

196 The generated chromate is then titrated with ferrous ammonium sulphate solution, using sodium

197 diphenylamine sulfonate $\left(\mathrm{C}_{12} \mathrm{H}_{10} \mathrm{NNaO}_{3} \mathrm{~S}\right)$ as an indicator:

$198 \mathrm{CrO}_{4}{ }^{2-}+8 \mathrm{H}^{+}+3 \mathrm{Fe}^{2+} \rightarrow 3 \mathrm{Fe}^{3+}+\mathrm{Cr}^{3+}+4 \mathrm{H}_{2} \mathrm{O}$

199 Oxidation reaction

$200 \quad 3 \mathrm{Fe}^{2+} \rightarrow 3 \mathrm{Fe}^{3+}+3 \mathrm{e}^{-}$

201 Reduction reaction

$202 \mathrm{CrO}_{4}{ }^{2-}+3 \mathrm{e}^{-}+8 \mathrm{H}^{+} \rightarrow \mathrm{Cr}^{3+}+4 \mathrm{H}_{2} \mathrm{O}$

203 In our approach, the Schreyer's titration method for solutions of ferrates has been modified,

204 because the standard procedure measurement for high $\mathrm{pH}(\mathrm{pH}>12)$ solutions is not compatible

205 with the indicator (diphenylamine sulfonate). For solid ferrate quantification these changes were 206 not necessary.

207 Standardization of ferrous ammonium sulphate, following the original Schreyer titration 208 method ${ }^{9,10}$ uses $5 \mathrm{~mL}$ of dichromate mixed with $150 \mathrm{~mL}$ of $\mathrm{H}_{2} \mathrm{O}, 60 \mathrm{~mL}$ of sulphuric acid 209 solution, and $15 \mathrm{~mL}$ of phosphoric acid solution in a $500 \mathrm{~mL}$ flask. A drop of the indicator is 210 then used in the stirred solution, which turns the solution color to purple. The standardization of 211 ferric ammonium sulphate is then achieved by titrating it against a known concentration of $\mathrm{Cr}$ 212 (VI) from a solution of dichromate, after which the purple solution turns green.

213 In the original methodology proposed by Schreyer ${ }^{14}$ (Figure 1), when a ferrate solution is

214 analyzed instead of solid ferrate, $5 \mathrm{~mL}$ of ferrate solution must be mixed in a solution containing $21520 \mathrm{~mL}$ of $10 \mathrm{M} \mathrm{NaOH}, 5 \mathrm{~mL}$ of $\mathrm{CrCl}_{3}$ solution and $5 \mathrm{~mL}$ of water. However, the $\mathrm{pH}$ is now very 
216 high and out of the range where the indicator works. For the solution to be titrated, a pH range

217 of 0 to 1 is needed to reach the optimum potential of the indicator which is $0.85 \mathrm{~V}$ vs SHE in $1 \mathrm{M}$

218 sulfuric acid. For this reason, we avoided using $\mathrm{NaOH}$ solution in order to keep the $\mathrm{pH}$ low

219 (between 0 to 1 ) and therefore in the optimal range for the indicator. We refer to this method as 220 the "modified Schreyer method".

221 In the modified Schreyer method the solution to be titrated is prepared by first mixing $5 \mathrm{~mL}$ of 222 ferrate solution generated at high $\mathrm{pH}(\mathrm{pH}>12))$ with $2 \mathrm{~mL}$ of chromic chloride solution in a 500 $223 \mathrm{~mL}$ flask. Once mixed, $150 \mathrm{~mL}$ of $\mathrm{DI} \mathrm{H}_{2} \mathrm{O}, 60 \mathrm{~mL}$ of sulphuric acid solution, and $15 \mathrm{~mL}$ of 224 phosphoric acid solution are all added to the flask. The previously standardized titrant is now 225 used to determine the concentration of the ferrate solution. At least two trials were performed, 226 and if repeatable results were not achieved, a third measurement was attempted. The following 227 equation was used to calculate the ferrate concentration in the solution:

231 of ferrate.

232 Although the titration method (such as the conventional Schreyer method or the modified

233 Schreyer method) is very accurate, it is not the most convenient method, particularly if a high 234 frequency of measurements is required. We find that these titrations take on average about 40 235 minutes to complete. In addition, this method requires at least $5 \mathrm{~mL}$ of ferrate solution for a 236 single measurement, thus making it difficult to do multiple quantifications with small samples, 237 and it involves hazardous chemicals like acids and toxic $\mathrm{Cr}$ (VI) ions. The cost of consumables 238 involved for this method is estimated to be about \$30 USD per trial. Therefore, an analytical 
239 technique, which uses a smaller sample size, is accurate, low cost, safe, and environmentally

240 friendly is still highly desired.

241 3.2. Direct Ferrate UV-VIS (Direct colorimetric method)

242 In this method absorbance of ferrates in $14 \mathrm{M} \mathrm{NaOH}$ is measured in the range wavelength

243 between 300 to $700 \mathrm{~nm}$. The absorbance curves were measured for a number of different ferrate

244 concentrations ranging from 0 to $692 \mu \mathrm{M}$. Each sample was prepared by adding a $20 \mu \mathrm{L}$ aliquot

245 of concentrated $0.0173 \mathrm{M}$ ferrate solution to a blank solution of $14 \mathrm{M} \mathrm{NaOH}$.

246 Figure 2 shows the absorption spectra of the samples with different ferrate

247 concentrations. The ferrate spectra show a maximum at $505 \mathrm{~nm}$ and two minima at $390 \mathrm{~nm}$ and

$248670 \mathrm{~nm}$ in close agreement with previous studies ${ }^{13}$. The shape of the adsorption curve was not

249 affected by the ferrate concentration.

250 Figure 3 shows the ferrate absorbance peaks at $505 \mathrm{~nm}$ versus the ferrate concentration.

251 The data were corrected for the blank absorbance by subtracting the $14 \mathrm{M} \mathrm{NaOH}$ absorbance

252 from the data. Error bars for the absorbance represent the standard deviation calculated from 3 or

253 more measurements.

254 The direct colorimetric method provides more accurate measurements for concentrations higher

255 than $100 \mu \mathrm{M}$. For example for a $17.3 \pm 0.1 \mathrm{mM}$ concentration using the titration method, the

256 value for direct UV-Vis measurement was $16.9 \pm 0.4 \mathrm{mM}$, which is in reasonable agreement.

257 This method also requires larger concentrations of ferrate to reach the same levels of absorbance

258 as the indirect spectral methods because the molar absorptive of Fe (VI) at $505 \mathrm{~nm}$ is low (1.5 x

$\left.25910^{3} \mathrm{M}^{-1} \mathrm{~cm}^{-1}, \mathrm{R}^{2}=0.99976\right)^{13}$. In addition, the ferrate solution tends to decompose to yield

260 colloidal Fe (III) oxides, which can interfere with the spectral measurements ${ }^{19}$. This problem can 
261 be avoided by centrifuging the sample prior to the adsorption measurement. The cost of 262 consumables involved for this method is low and estimated to be about \$0.1 USD per test.

264 In this method, colorless ABTS reacts with Fe (VI) to form the green radical cation $\mathrm{ABTS}^{+}$.

265 The reaction of Fe (VI) with ABTS has a 1:1 stoichiometry in the presence of an excess of $266 \mathrm{ABTS}^{20}$

$267 \mathrm{Fe}(\mathrm{VI})+\mathrm{ABTS} \rightarrow \mathrm{Fe}(\mathrm{V})+\mathrm{ABTS}^{+}$

268 The procedure used by Lee et. al ${ }^{20}$ involves adding, $5 \mathrm{~mL}$ of a $\mathrm{pH} 4.1$ buffer solution, $1 \mathrm{~mL}$ of 269 ABTS reagent and a ferrate sample volume between $5 \mu \mathrm{L}$ and $25 \mu \mathrm{L}$ to a $25 \mathrm{ml}$ volumetric 270 flask. The $\mathrm{Na}_{2} \mathrm{HPO}_{4} /$ Borate buffer $\mathrm{pH} 9.1$ solution is then added until the volume of the solution 271 in the flask is $25 \mathrm{ml}$. The solution will change color to green due to the formation of the ABTS $^{+}$ 272 radical. The absorbance of the blank solution and the ferrate solution are measured. Ferrate 273 solutions with different concentrations were chosen to cover a wide range of absorbance.

$274 \quad$ Figure 4 shows the absorption spectra of $\mathrm{ABTS}^{+}$for different ferrates concentrations.

275 The maxima of the spectra for ABTS occur at about $415 \mathrm{~nm}$ in agreement with the results 276 reported by Lee et. al ${ }^{20}$. However, a small difference in the shape of the absorption curves can 277 be noticed with the presence of a small peak at $390 \mathrm{~nm}$. This may be due to differences in the 278 procedure that were used, Lee et. al $^{20}$ used solid ferrate dissolved in a $\mathrm{pH} 9$ buffer solution, 279 whereas we used a high $\mathrm{pH}$ ferrate solution without a buffer for our experiments.

280 Figure 5 shows the absorbance peaks obtained at $415 \mathrm{~nm}$ for different ferrate concentrations.

281 Error bars for the absorbance represent the standard deviation calculated from 3 or more 282 measurements. The data has been corrected by subtraction of the blank absorbance. The ABTS 283 method leads to highly accurate measurements for low ferrate concentrations as compared with 
284 the titration method. For example, for a $17.3 \pm 0.1 \mathrm{mM}$ ferrate concentration (using the titration 285 method) the value for ABTS method was $17.32 \pm 0.03 \mathrm{mM}$.

286 The $\mathrm{ABTS}^{+}$radical has a higher molar absorptivity than ferrate, allowing for better sensitivity 287 and more accurate results with low ferrate concentrations The molar absorptivity is $3.7 \times 10^{4} \mathrm{M}^{-1}$ $288 \mathrm{~cm}^{-1}\left(\mathrm{R}^{2}=0.99858\right)$ for ABTS. A ferrate solution of $700 \mu \mathrm{M}$ has an absorption value of around 1 , 289 whereas $\mathrm{ABTS}^{+}$reaches the same value of absorption with a much smaller ferrate concentration 290 of only $35 \mu \mathrm{M}$. This is more than an order of magnitude enhancement in the sensitivity.

291 One of the major drawbacks of the ABTS method is the instability of the solution. After about 30 292 minutes, at room temperature, the ABTS solution begins to decompose changing its blank 293 absorption values. When the ABTS solution has a slightly higher blank absorption than 0.02 at $294415 \mathrm{~nm}$ and in a $10 \mathrm{~cm}$ path length (about 0.2 in $10 \mathrm{~cm}$ path length) it must be replaced ${ }^{18}$ If this 295 decomposition reaction occurs significantly before mixing with ferrate, the technique will not 296 give an accurate reading for ferrate. Therefore, it is essential to use fresh ABTS solutions for 297 accurate determination of the ferrate concentrations. Furthermore, analyzing multiple samples is 298 time consuming and generates a lot of organic chemical waste coming from ABTS. The cost of 299 consumables involved for this method is estimated to be about \$3 USD per trial.

\subsection{Indirect NaI UV-VIS method}

301 This is a very promising spectrophotometric method that has been developed for quantification 302 of ferrates. The method uses sodium iodide (NaI) solution to determine concentrations of Fe (VI)

303 at low $(<10 \mu \mathrm{M})$ concentrations levels in water ${ }^{12,13}$. It is thus ideally suited for applications of

304 ferrates for water treatment. The method relies on the reaction of the ferrate solution with an 305 excess amount of $\mathrm{NaI}$. Upon reaction the purple color of Fe (VI) disappears instantaneously and 306 a yellow solution appears indicating the formation of $\mathrm{I}_{3}{ }^{-}$ions: 
308 This method is generally applicable for a $\mathrm{pH}$ range of 5.5 to $9.3^{12}$. However, for testing at $\mathrm{pH}$

309 higher than 9 no $\mathrm{I}_{3}^{-}$peak was observed. To expand the range of operating $\mathrm{pH}$ conditions, we 310 modified the methodology by using a phosphate-based buffer with a $\mathrm{pH}=9$. We used this 311 particular buffer to keep the $\mathrm{pH}$ constant, because phosphates stabilizes Fe (III) avoiding the 312 formation of hydroxides that can interfer in the UV-VIS reading ${ }^{18}$.

313 In the original methodology, solid ferrate is dissolved only in the NaI solution. In this modified 314 methodology $\mathrm{NaI}$ was dissolved to a $0.1 \mathrm{M}$ concentration in a buffer solution prepared with 955 $315 \mathrm{~mL}$ of $0.1 \mathrm{M}$ disodium hydrogen phosphate and $45 \mathrm{~mL} 0.1 \mathrm{M} \mathrm{HCl}$. A $25 \mathrm{~mL}$ volume of this 316 buffer solution is then dosed with aliquots of the ferrate solution to reach concentrations between

3172 to $30 \mu \mathrm{M}$ and the UV-VIS spectra were then recorded. Figure 6 shows the absorption spectra 318 for a number of different ferrate concentrations with the maximum absorption peak at about 351 $319 \mathrm{~nm}$, in agreement with previous studies ${ }^{13}$. The shape of the absorption curves for $\mathrm{I}_{3}^{-}$is not 320 affected by the Fe (VI) dosage range.

321 Figure 7 shows the peak maxima of the absorbance curves versus the ferrate concentration $(0$ $322 \quad 28.52 \mu \mathrm{M})$. The blank absorbance has been subtracted from the data points. The increase in the 323 absorbance peak at $351 \mathrm{~nm}$ is linear with respect to the concentration of Fe (VI). The molar 324 absorptivity at $351 \mathrm{~nm}$ is $0.0396 \mu \mathrm{M} \mathrm{cm}^{-1}\left(\mathrm{R}^{2}=0.9972\right)$. This value is slightly higher than the 325 reported value of $0.0291 \mu \mathrm{M} \mathrm{cm}^{-1} 12,13$. Discrepancies may be attributed to the different 326 experimental conditions such as the higher $\mathrm{pH}$ and the use of the buffer solution to keep the $\mathrm{pH}$ 327 constant. Nevertheless, the modified NaI method gives an accurate measurement of the ferrate 328 concentration. For example, for a $17.3 \pm 0.1 \mathrm{mM}$ ferrate concentration (using titration), the value 329 for the NaI method was $17.27 \pm 0.08 \mathrm{mM}$. 
330 Similar to the ABTS method, the NaI method has been developed due to the higher molar

331 absorptivity of the $\mathrm{I}_{3}{ }^{-}$ion compared to ferrate, allowing for higher precision as well as more

332 accurate readings at low concentrations of ferrate. The NaI method requires a $27 \mu \mathrm{M}$ solution of

333 ferrate for an absorbance around 1, compared to the $700 \mu \mathrm{M}$ concentration required by direct

334 UV-Vis ferrate spectrophotometry. Compared to the ABTS indirect method, the NaI holding

335 solution can be left for extended periods of time without degrading or reacting which makes it

336 feasible method for use in multiple samples requiring more time. The NaI method can also be

337 carried out using just $4 \mathrm{~mL}$ of a $0.1 \mathrm{M} \mathrm{NaI}$ buffer $\mathrm{pH} 9$ solution, decreasing the quantity of

338 generated waste. The cost of consumables involved for this method is estimated to be about $\$ 0.1$

339 USD per trial.

\subsection{Impact of Fe (III) on ferrate solutions quantification.}

342 The impact of Fe (III) on quantification of electrochemically generated ferrate was also 343 studied.

344 We waited 24 hours keeping the samples at $21^{\circ} \mathrm{C}$ in order to reduce Fe (VI) to Fe (III) and 345 then study the effect of naturally produce Fe (III) on ferrate degradation. After this period of 346 time, some samples were centrifuged for 20 minutes at $2000 \mathrm{rpm}$. Centrifuged and non347 centrifuged samples were quantified by the chemical titration method as well as by 348 spectrophotometry. The ferrate concentrations of the centrifuged and non-centrifuged samples, 349 using the chemical titration method, were $1.25 \mathrm{mM}$ and $1.11 \mathrm{mM}$, respectively. The difference 350 between centrifuged and non- centrifuged data could partially be explained by the fact that the 351 non- soluble Fe (III) compounds, which are suspended in the non- centrifuged sample and which 
352 do not react during titration, will be pipetted, thus occupying volume that would otherwise be 353 ferrate solution.

354 The effect of Fe (III) on quantification of ferrate solutions was also tested using 355 spectrophotometric techniques. For the direct colorimetric method the concentration of the 356 centrifuged ferrate solution was $1.22 \mathrm{mM}$ while the non-centrifuged solution had a concentration 357 of $1.08 \mathrm{mM}$. The $\mathrm{NaI}$ and ABTS methods measure the absorbance of the $\mathrm{I}_{3}{ }^{-}$and $\mathrm{ABTS}^{+}$ions, 358 respectively, which are generated as a result of chemical reactions with ferrate. This allows for 359 the ability to account only for the presence of ferrate while any Fe (III) ions are left unreacted. In 360 addition, the indirect methods used a phosphate buffer were used. Phosphates stabilize Fe (III) by 361 surface complexation ${ }^{21}$, avoiding the formation of hydroxides that interfer in the UV-VIS 362 reading ${ }^{18}$

363 The NaI and ABTS methods were tested using 5, 15 and $25 \mu \mathrm{L}$ concentration aliquots of 364 ferrate. Figure 8 shows the effects of centrifuging on the concentration of ferrate quantified, 365 using the NaI and ABTS methods.

366 In the case of $\mathrm{NaI}$ (Figure $8 \mathrm{a}$ ) for $5 \mu \mathrm{L}$, the centrifuged ferrate solution resulted in an 367 absorbance of 0.170 , compared to the non-centrifuged value of 0.120 , corresponding to $4.2 \mu \mathrm{M}$ 368 and $3.1 \mu \mathrm{M}$ respectively. A similar effect was obtained with the ABTS method, i.e., an 369 absorbance of $0.140(3.5 \mu \mathrm{M})$ and $0.120(2.9 \mu \mathrm{M})$ for the centrifuged and non-centrifuged ferrate 370 solutions, respectively.

371 The impact of centrifuging on the absorbance for the ABTS method here is less pronounced 372 than for the NaI method, however in both cases the different between centrifuged and non373 centrifuged was lower than $1 \mu \mathrm{M}$. 
374 Centrifuging the ferrate solution in the presence of Fe (III) helps in physical separation of

375 insoluble species from the solution and leads to higher absorbance values.

3.6. Comparison of the various different quantification techniques.

378 Table 1 shows a summary of the four different ferrate quantification methods investigated 379 here.

380 Parameters considered were as follows : 1) Preparation Time: the time necessary for preparing 381 all the solutions required for the quantification method, 2) Test Time: the time required to 382 quantify a sample, 3) Waste per Sample: chemical waste generated per sample, 4) Toxicity: the 383 degree of toxicity for the waste generated, 5) Stability: the stability of each solution used in the 384 quantification methods, 6) Accuracy: accuracy of the measurement (as compared to the titration 385 method which is considered to be the most accurate method), 7) Precision: precision of the 386 measurement (defined as the repeatability of the measurement), 8) Range: the range of ferrate 387 concentration over which the quantification method works well, and 9) Cost per sample: the cost 388 of all the consumables used per sample measurement, (based on Fisher Scientific's prices).

389 The following summary points can be made about the different ferrate quantification methods:

390 1) The chemical titration method for quantification is very accurate, but the method requires

391 large amounts of acid and uses toxic Cr (VI). This method produces large amounts of chemical 392 wastes (chromium, sulphuric acid and phosphoric acid) that are hazardous. The method is also 393 time consuming and inefficient for a) the measurement of multiple samples in a short time period 394 and for b) low ferrate concentration samples. 
395 2) The direct ferrate UV-Vis technique provides adequate accuracy and moderate precision.

396 Due to its low molar absorptivity, it is not possible to quantify samples with concentrations 397 smaller than $70 \mu \mathrm{M}$ of Fe (VI) by the direct UV-Vis colorimetric method.

398 3) The indirect ABTS-based spectrophotometric method is a very simple, efficient, and a 399 highly accurate method. However, the ABTS solution is not stable and degradation of the ABTS 400 solution will lead to erroneous results. For longer-time ferrate quantification, a stable solution is 401 necessary.

402 4) The indirect NaI UV-Vis method is a very good option because it is stable, easy to make, 403 environmentally benign, and does not lead to harmful wastes. For UV-Vis measurements, 404 smaller concentrations of ferrate are required resulting in smaller concentrations of ferrate that 405 can be detected, thus making it ideal for water treatment applications. NaI can be left for 406 extended periods of time without any degradation, making it ideal for ferrate quantification. 407 Furthermore, the costs associated with this technique, compared to the ABTS method, are 408 significantly lower. The cost of $\mathrm{NaI}$ is about \$1 USD per gram whereas that of ABTS is about $409 \$ 60$ USD per gram. The waste generated from this method is also significantly less hazardous 410 than that of other quantification methods.

\section{4. Conclusions}

413 We have investigated four different analytical methods for quantification of ferrates with 414 particular attention to the use of ferrates for water treatment applications. These four methods 415 include: 1) chemical titrimetric analysis, 2) and the spectrometric techniques of direct ferrate 416 UV-Vis, 3) indirect UV-Vis ABTS, and 4) indirect UV-Vis NaI. These techniques were initially 417 developed for chemical ferrates which can be dissolved to form the optimal solution 418 concentration for each measurement method. In the research reported here, we have evaluated 
419 the suitability of these "chemical ferrate" methods for "electrochemical ferrates" and made

420 modifications where necessary. The key for successful measurement of electrochemically

421 generated ferrate appears to be the modification of these techniques to keep the $\mathrm{pH}$ at the

422 optimum value for each quantification method.

423 The advantages and disadvantages of each quantification method and their respective modified

424 version(s) were discussed. Although the commonly used ABTS approach is very simple,

425 efficient and highly accurate, the ABTS solution is not stable, which poses a problem for ferrate

426 quantification. For a quantification procedure with a longer required time span, a stable solution

427 is necessary. The modified indirect NaI UV-Vis method is an ideal approach, because it is stable,

428 easy to prepare, it does not lead to harmful or significant waste, it is low cost, and it has high

429 accuracy and precision, and it is suitable for low $(\mu \mathrm{M})$ ferrate concentrations. In the presence of

430 Fe (III), the additional step of sample centrifuging was shown to be an important step for

431 improving measurement accuracy.

\section{Acknowledgments}

433 We like to acknowledge the Res'eau WaterNET for funding support. MS acknowledges NSERC 434 for USRA undergraduate scholarship.

\section{References}

436 (1) Sharma, V. K.; Kazama, F.; Jiangyong, H.; Ray, A. K. 2005, No. Vi, 45.

437 (2) Kristian L. Dubrawskia, Macarena Cataldo, Zachary Dubrawskia, Asit Mazumderb, David 438 P. Wilkinsona, and M. M. Sci. Total Environ. Elesevier 2016.

439 (3) Jiang, J.-Q. J. Chem. Technol. Biotechnol. 2014, 89 (2), 165. 
440 (4) Alsheyab, M.; Jiang, J.-Q.; Stanford, C. J. Environ. Manage. 2009, 90 (3), 1350.

441 (5) Jiang, J.-Q.; Lloyd, B. Water Res. 2002, 36 (6), 1397.

442 (6) Licht, S.; Yu, X.; Qu, D. In Ferrates; pp 268-291.

443 (7) Mácová, Z.; Bouzek, K.; Híveš, J.; Sharma, V. K.; Terryn, R. J.; Baum, J. C. Electrochim. $444 \quad$ Acta 2009, $54(10), 2673$.

445 (8) Jiang, J.-Q. J. Chem. Technol. Biotechnol. 2014, 89 (2), 165.

446 (9) Cañizares, P.; Arcís, M.; Sáez, C.; Rodrigo, M. a. Electrochem. commun. 2007, 9 (9), 4472286.

448 (10) Zhang, C.; Liu, Z.; Wu, F.; Lin, L.; Qi, F. Electrochem. commun. 2004, 6 (11), 1104.

449 (11) Bouzek, K.; Schmidt, M. J.; Wragg, A. a. Electrochem. commun. 1999, 1 (9), 370.

450 (12) Luo, Z.; Strouse, M.; Jiang, J.-Q.; Sharma, V. K. J. Environ. Sci. Health. A. Tox. Hazard. $451 \quad$ Subst. Environ. Eng. 2011, $46(5), 453$.

452 (13) Licht, S.; Naschitz, V.; Halperin, L.; Halperin, N.; Lin, L.; Chen, J.; Ghosh, S.; Liu, B. J. $453 \quad$ Power Sources 2001, 101 (2), 167.

454 (14) J. M. SCHREYER, G. W. THOMPSON', A. L. T. O. Anal. Chem. 1950, 22, 1426.

455 (15) Golovko, D. a.; Sharma, V. K.; Pavlova, O. V.; Belyanovskaya, E. a.; Golovko, I. D.; 456 Suprunovich, V. I.; Zboril, R. Cent. Eur. J. Chem. 2011, 9 (5), 808.

457 (16) Golovko, D. a.; Sharma, V. K.; Suprunovich, V. I.; Pavlova, O. V.; Golovko, I. D.; $458 \quad$ Bouzek, K.; Zboril, R. Anal. Lett. 2011, 44 (7), 1333.

459 (17) Am, J.; York, N.; August, R. 1986, No. 6, 523. 
460 (18) Lee, Y.; Yoon, J.; von Gunten, U. Water Res. 2005, 39 (10), 1946.

461 (19) Luo, Z.; Strouse, M.; Jiang, J.-Q.; Sharma, V. K. J. Environ. Sci. Health. A. Tox. Hazard. $462 \quad$ Subst. Environ. Eng. 2011, $46(5), 453$.

463 (20) Lee, Y.; Yoon, J.; von Gunten, U. Water Res. 2005, 39 (10), 1946.

464 (21) Jiang, Y.; Goodwill, J. E.; Tobiason, J. E.; Reckhow, D. a. Environ. Sci. Technol. 2015, $465 \quad$ No. Iii.

466

467

468

469

470

471

472

473

474

$475 \quad$ Figures and Captions

476

477 
(a) Titrimetric Analysis

Titrant Standardization

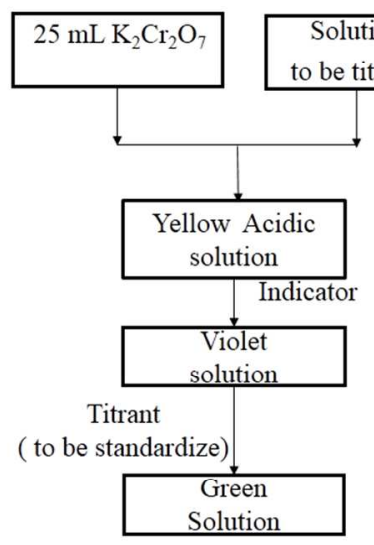

(c) Indirect ABTS UV-Vis method

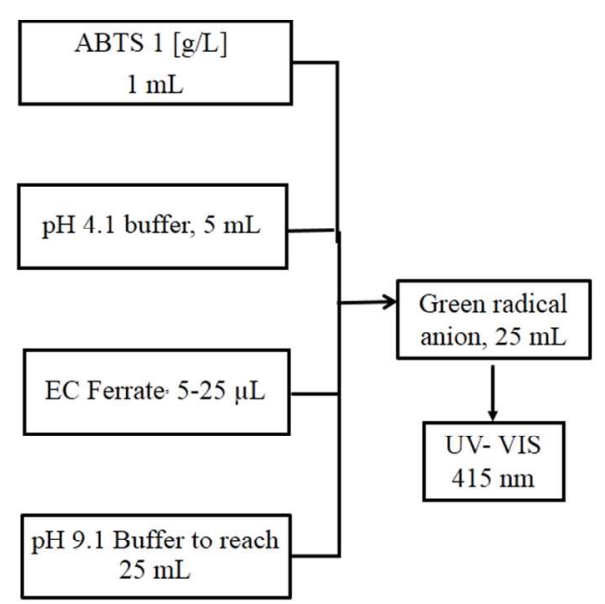

$\mathrm{Fe}$ (VI) Quantification (b) Direct Ferrate UV-Vis method

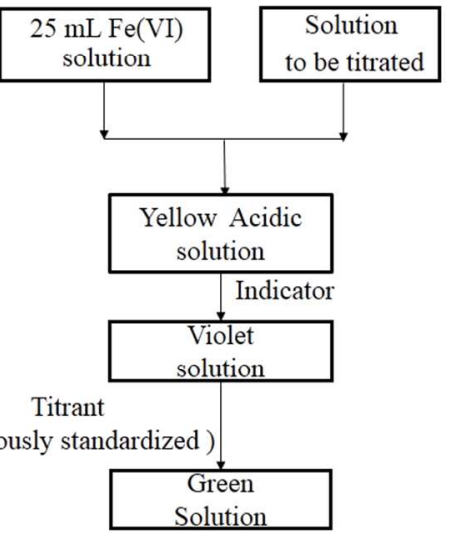

(c) Indirect ABTS UV-Vis method

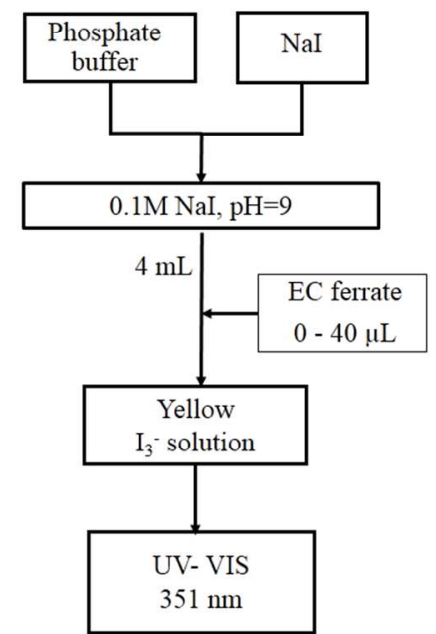

479 Figure 1. Flow diagrams for different quantification techniques (a) Titrimetric Analysis, (b)

480 Direct UV-Vis method, (c) Indirect ABTS UV-Vis method, and (d) Indirect NaI UV-Vis method. 


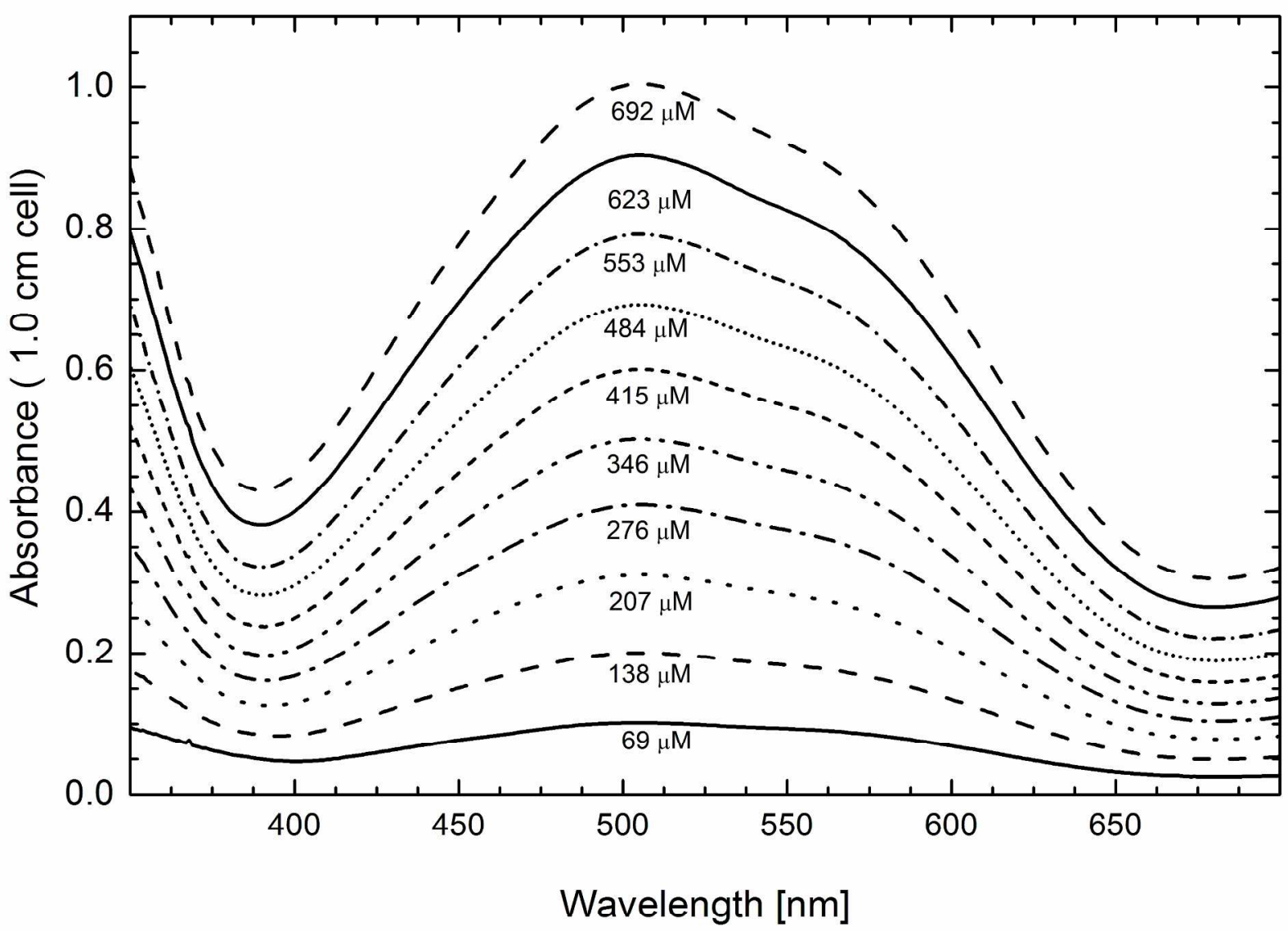

483 Figure 2. Absorption spectra for different concentrations of ferrate in $10 \mathrm{~mL}$ of a $14 \mathrm{M} \mathrm{NaOH}$ 484 solution, using a $1 \mathrm{~cm}$ path length cell. 


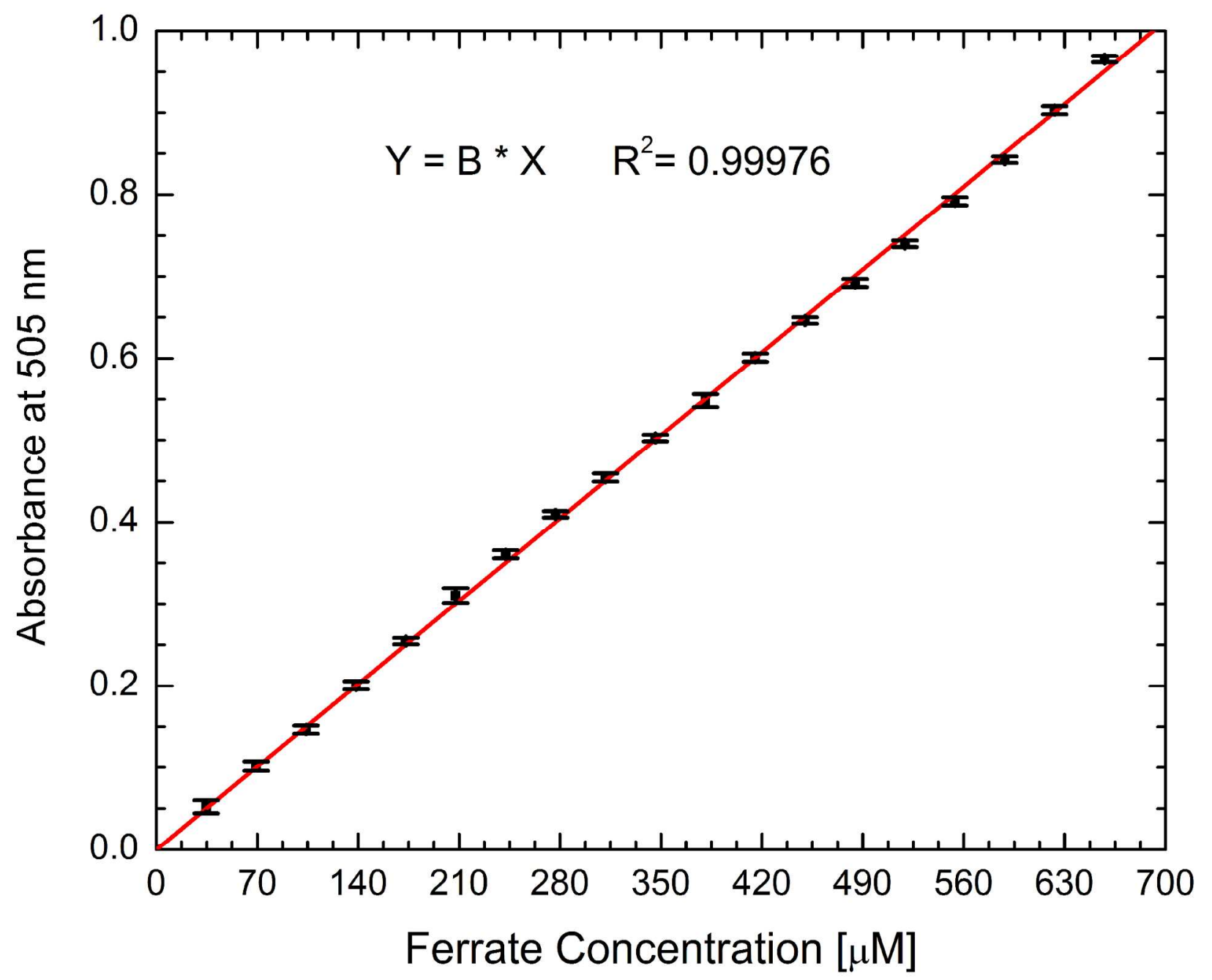

487

488 Figure 3. $505 \mathrm{~nm}$ absorbance of ferrate at different concentrations in a $14 \mathrm{M} \mathrm{NaOH}$ solution, 489 using a $1 \mathrm{~cm}$ path length cell. 


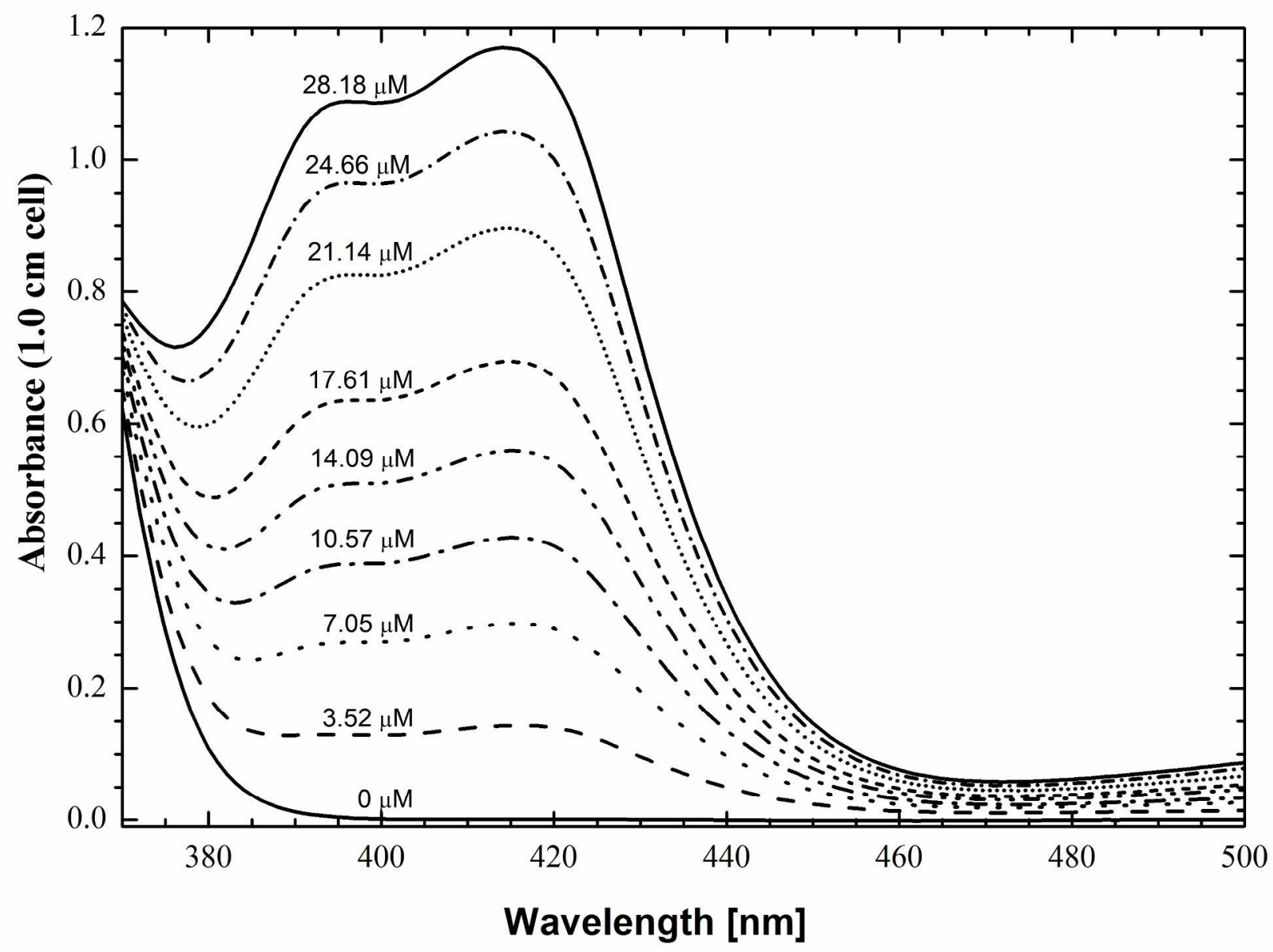

493

494 Figure 4: Absorption spectra of $\mathrm{ABTS}^{+}$for different concentrations of ferrates using a $1 \mathrm{~cm}$ path 495 length cell.

496

497 


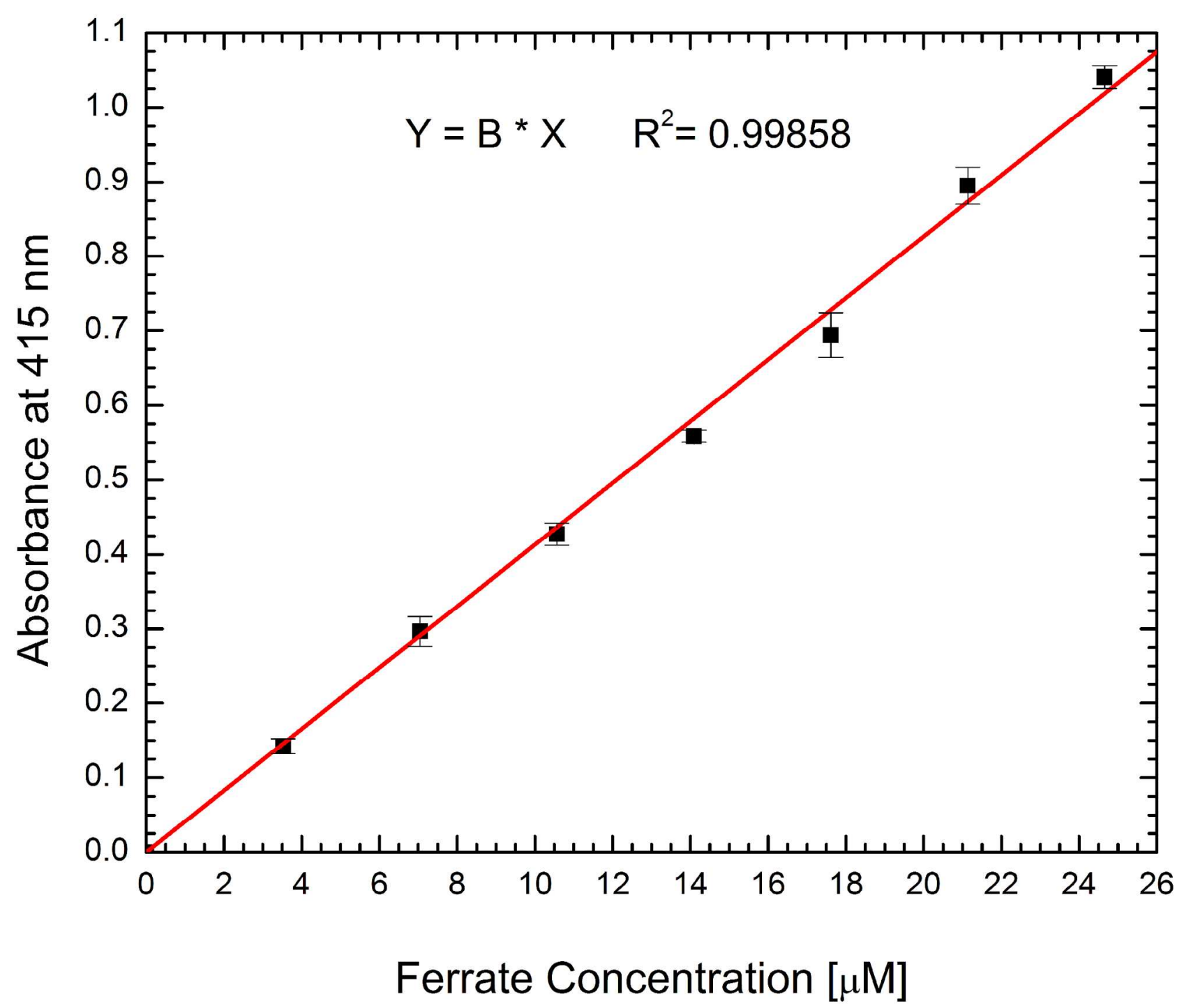

498

499 Figure 5: $415 \mathrm{~nm}$ absorbance of $\mathrm{ABTS}^{+}$for different concentrations of ferrate solution, using a 1 $500 \quad$ cm path length cell. 


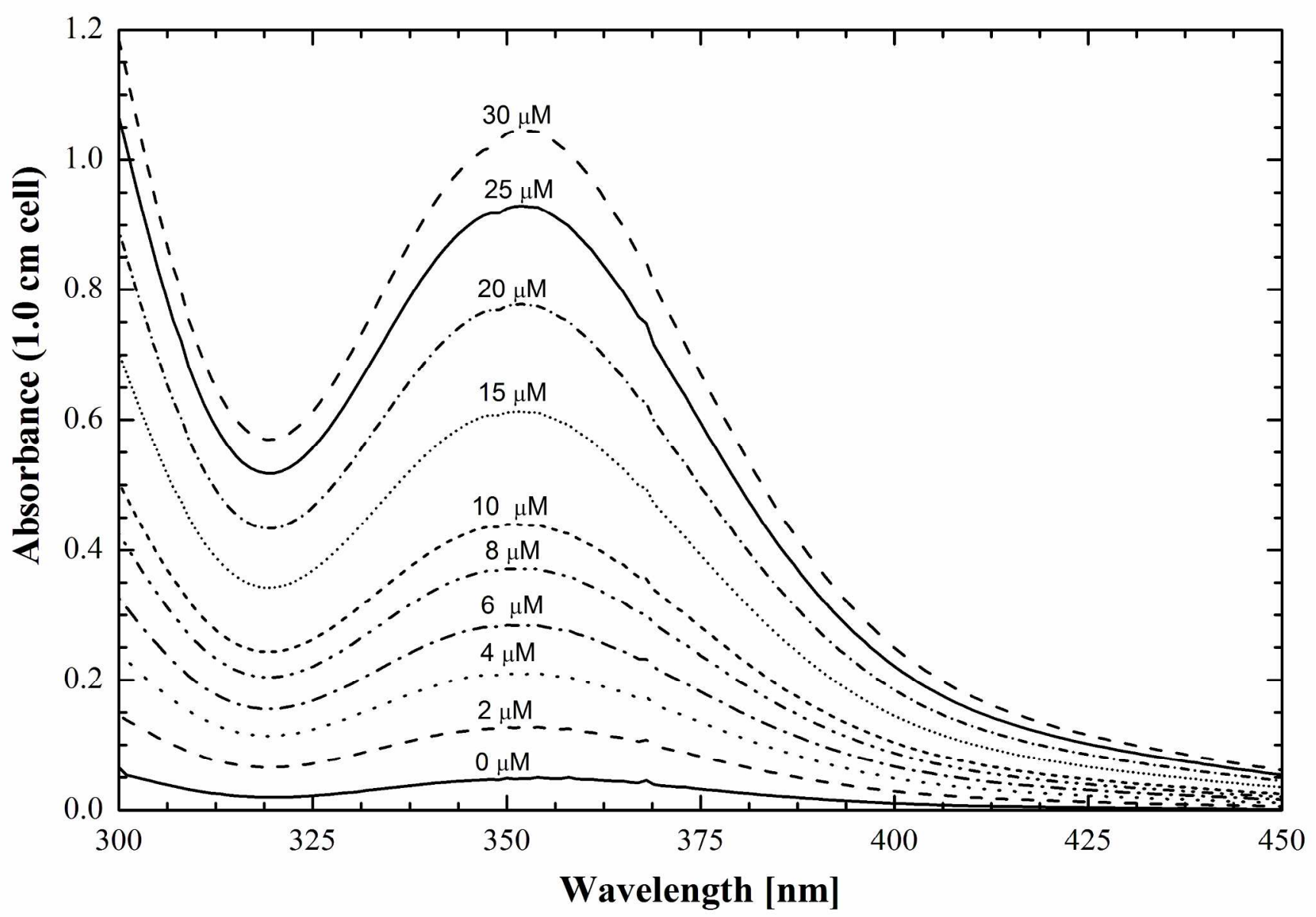

502 Figure 6: Absorption spectra for different concentrations of ferrate in $0.1 \mathrm{M}$ NaI solution 503 buffered to $\mathrm{pH} \mathrm{9,} \mathrm{using} \mathrm{a} 1 \mathrm{~cm}$ path length cell. 


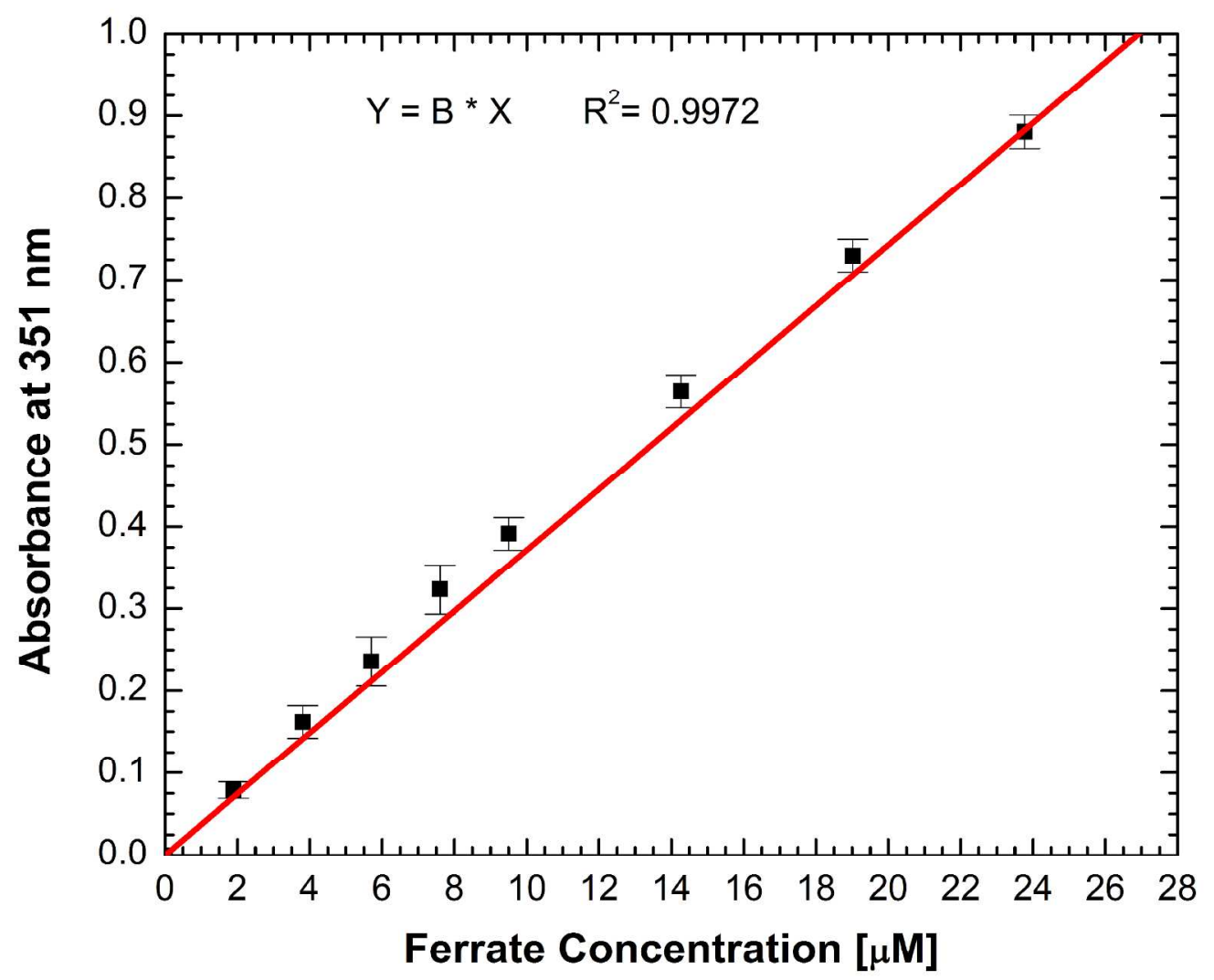

505

506 Figure 7: Absorbance obtained at $351 \mathrm{~nm}$ for different concentrations of ferrate in $0.1 \mathrm{M}$ of NaI 507 solution buffered to $\mathrm{pH} 9$ using a $1 \mathrm{~cm}$ path length cell. 

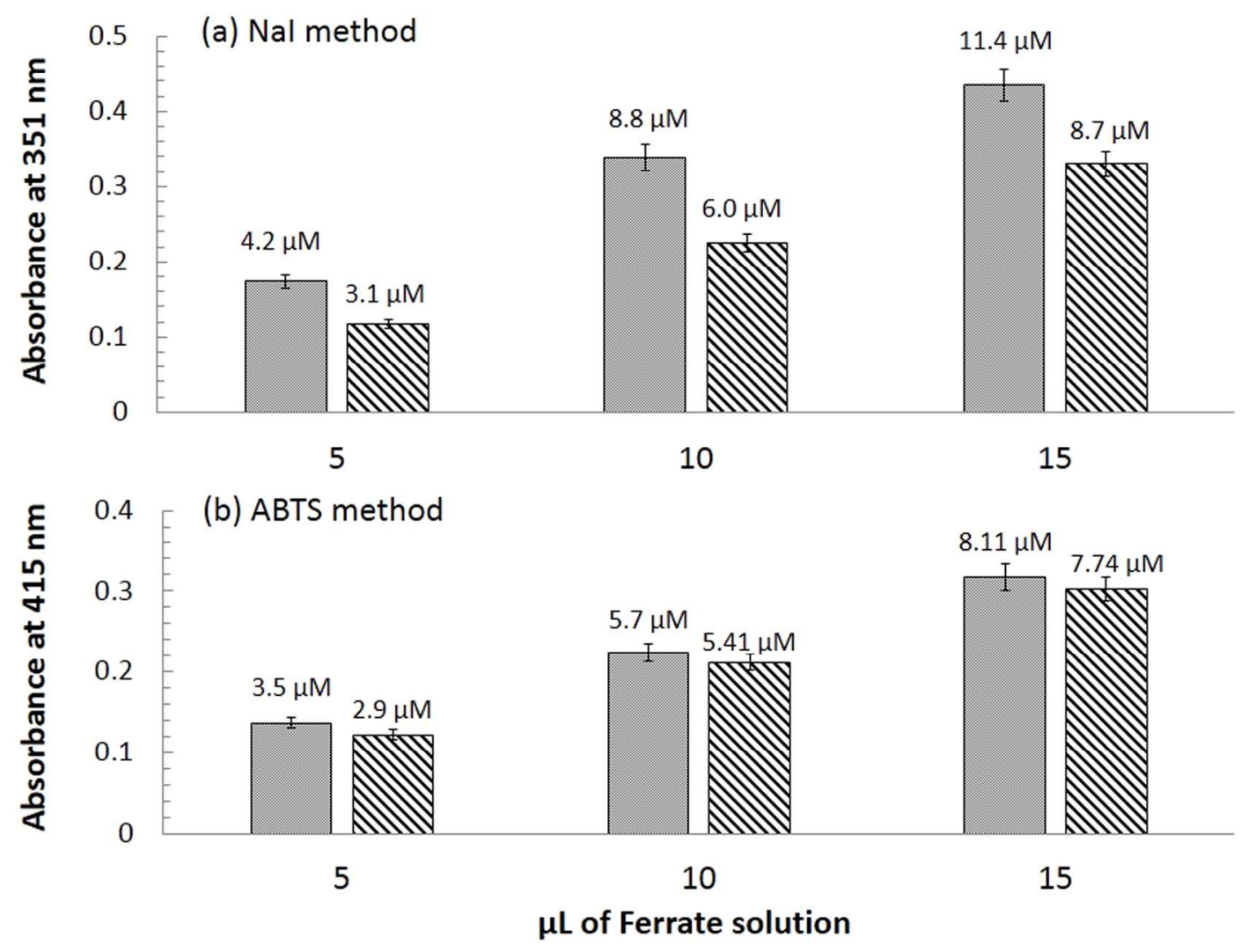

511 Figure 8: The effects of centrifuging on the concentration of ferrate, quantified using the NaI 512 and ABTS methods. 
Table 1: Comparison of ferrate quantification methods.

\begin{tabular}{|c|c|c|c|c|c|}
\hline \multicolumn{2}{|c|}{ Parameter } & $\begin{array}{l}\text { Chemical } \\
\text { Modified } \\
\text { Titration }\end{array}$ & $\begin{array}{c}\text { Direct Ferrate } \\
\text { UV-VIS }\end{array}$ & $\begin{array}{c}\text { Indirect NaI } \\
\text { Modified UV-VIS }\end{array}$ & $\begin{array}{c}\text { Indirect } \\
\text { ABTS UV-VIS }\end{array}$ \\
\hline \multicolumn{2}{|c|}{ Preparation time } & $1 \mathrm{~h}$ & $15 \mathrm{~min}$ & 20 mins & $30 \mathrm{~min}$ \\
\hline \multicolumn{2}{|l|}{ Test Time } & $30 \mathrm{~min}$ & $1 \mathrm{~min}$ & $3 \mathrm{~min}$ & $5 \mathrm{~min}$ \\
\hline \multicolumn{2}{|c|}{$\begin{array}{l}\text { Generated } \\
\text { Waste per sample }\end{array}$} & $\begin{array}{l}\text { 1L (chromium } \\
\text { / acid) }\end{array}$ & 4 to $10 \mathrm{~mL} \mathrm{NaOH}$ & $\begin{array}{l}4 \text { to } 25 \mathrm{~mL} \\
\mathrm{NaI}\end{array}$ & $\begin{array}{l}25 \mathrm{~mL} \text { ABTS } \\
\text { (Organic waste) }\end{array}$ \\
\hline \multicolumn{2}{|l|}{ Toxicity } & High & low & Medium & Medium \\
\hline \multirow[t]{2}{*}{$U V-V i s$} & Peak $\lambda$ & NA & $505 \mathrm{~nm}$ & $351 \mathrm{~nm}$ & $415 \mathrm{~nm}$ \\
\hline & $\begin{array}{c}\text { Molar } \\
\text { Absorptivity }\end{array}$ & NA & $1.5 \times 10^{3} \mathrm{M}^{-1} \mathrm{~cm}^{-1}$ & $4.1 \times 10^{4} \mathrm{M}^{-1} \mathrm{~cm}^{-1}$ & $3.7 \times 10^{4} \mathrm{M}^{-1} \mathrm{~cm}^{-1}$ \\
\hline \multicolumn{2}{|l|}{ Stability } & low & moderate & high & low \\
\hline \multicolumn{2}{|l|}{ Accuracy } & Very good & Moderate & Very good & Very Good \\
\hline \multicolumn{2}{|l|}{ Precision } & Very good & Moderate & Good & Good \\
\hline \multicolumn{2}{|c|}{ Range $\left[\mathrm{FeO}_{4}\right]^{2-}$} & $>0.2 \mathrm{mM}$ & $>70 \mu \mathrm{M}$ & $>0.25 \mu \mathrm{M}$ & $>0.03 \mu \mathrm{M}$ \\
\hline \multicolumn{2}{|c|}{$\begin{array}{l}\text { Cost per sample } \\
\text { (consumables) }\end{array}$} & $\$ 30$ USD & $\$ 0.1$ USD & \$3 USD & $\$ 0.5$ USD \\
\hline
\end{tabular}

522 